Tropical Journal of Pharmaceutical Research February 2020; 19 (2): 219-225

ISSN: $1596-5996$ (print); 1596-9827 (electronic)

(C) Pharmacotherapy Group, Faculty of Pharmacy, University of Benin, Benin City, 300001 Nigeria.

Available online at http://www.tjpr.org

Original Research Article

http://dx.doi.org/10.4314/tjpr.v19i2.1

\title{
Hydroxychloroquine enhances anticancer effect of DOX/folate-phytosterol-carboxymethyl cellulose nanoparticles in A549 lung cancer cells
}

\author{
Ezzat H Elshazly ${ }^{1,2}$, Song Zhang ${ }^{1}$, Lizhen $\mathrm{Yu}^{1,3}$, Yue Zhang ${ }^{1,4}$, Lixia Ke ${ }^{1}$, Renmin \\ Gong ${ }^{1 *}$ \\ ${ }^{1}$ College of Life Science, Anhui Normal University, Wuhu, 241000, PR China, ${ }^{2}$ Department of Botany \& Microbiology, Faculty of \\ Science, Al Azhar University, Assiut 71524, Egypt, ${ }^{3}$ School of Pharmacy, Wannan Medical College, ${ }^{4}$ School of Forensic \\ Medicine, Wannan Medical College, Wuhu 241002, PR China
}

*For correspondence: Email: klixia@mail.ahnu.edu.cn; Tel: +86-15555305589

Sent for review: 6 October 2019

Revised accepted: 26 January 2020

\begin{abstract}
Purpose: To study the in vitro anticancer effect of doxorubicin-loaded folate-phytosterol-carboxymethyl cellulose nanoparticles (DOX/FPCMC NPs), alone and in combination with the antimalarial drug hydroxychloroquine (HCQ) on human lung cancer cells (A549 cells).

Methods: Human lung adenocarcinoma A549 cell line was treated with blank FPCMC NPs, HCQ, free $D O X, D O X / F P C M C N P S$, free DOX + HCQ or DOX/FPCMC NPs + HCQ. The concentrations of HCQ, DOX and FPCMC NPs varied within the ranges of 20-120 $\mu \mathrm{mol} / \mathrm{L}, 2-12 \mathrm{mg} / \mathrm{L}$ and $50-500 \mathrm{mg} / \mathrm{L}$, respectively. Cell viability and free folate competitive inhibition were determined using MTT assay. Cell proliferation and migration were investigated with wound healing assay, while confocal laser scanning microscopy (CLSM) was used to determine cellular uptake of drugs.

Results: In all formulations, the DOX/FPCMC NPs + HCQ produced the highest cytotoxicity in A549 cells due to high cytotoxicity arising from folate-receptor-mediated endocytosis and HCQ-induced inhibition of autophagy. Free folate competitively inhibited the cytotoxicity of DOX/FPCMC NPS on A549 cells. Wound healing assay showed that A549 cells treated with DOX/FPCMC NPs + HCQ had the lowest cell levels of proliferation and migration capacity. The cellular uptake of DOX/FPCMC NPs by A549 cells was higher than that of free DOX.

Conclusion: The combination of DOX/FPCMC NPs and HCQ produced the best antitumor effect and had a promising potential for reversal of MDR
\end{abstract}

Keywords: Folate-phytosterol-carboxymethyl cellulose, Doxorubicin, Hydroxychloroquine, Anticancer, Lung cancer

\begin{abstract}
This is an Open Access article that uses a fund-ing model which does not charge readers or their institutions for access and distributed under the terms of the Creative Commons Attribution License (http://creativecommons.org/licenses/by/4.0) and the Budapest Open Access Initiative (http://www.budapestopenaccessinitiative.org/read), which permit unrestricted use, distribution, and reproduction in any medium, provided the original work is properly credited.

Tropical Journal of Pharmaceutical Research is indexed by Science Citation Index (SciSearch), Scopus, International Pharmaceutical Abstract, Chemical Abstracts, Embase, Index Copernicus, EBSCO, African Index Medicus, JournalSeek, Journal Citation Reports/Science Edition, Directory of Open Access Journals (DOAJ), African Journal Online, Bioline International, Open-J-Gate and Pharmacy Abstracts
\end{abstract}

\section{INTRODUCTION}

Cancer is a serious worldwide public health issue that causes more than 8 million deaths every year. Currently, the most effective and popular treatment for cancer is chemotherapy. Chemotherapy inhibits development of tumor through the cytotoxicity of intravenously-injected, 
small-molecule anticancer drugs. However, the antitumor drugs are not specifically targeted to cancer cells. Therefore, the drugs kill not only cancer cells, but also normal cells [1]. Multidrug resistance (MDR) is one of the factors responsible for failure of cancer chemotherapy. Indeed, studies have shown that MDR results in treatment failure among $90 \%$ of patients with metastatic cancer [2].

Doxorubicin (DOX) is a broad-spectrum anticancer drug used for treating many types of tumors such as acute lymphoblastic and myeloblastic leukemias, malignant lymphomas, as well as breast, ovarian, prostate, bladder, gastric, and bronchogenic cancers. However, the use of DOX in tumor treatment is frequently associated with MDR. The antimalarial drug chloroquine (CQ) and its derivative hydroxychloroquine (HCQ), as autophagy inhibitors, have great significance in cancer therapy [3, 4]. The use of CQ (or HCQ) alone or combined with other chemical agents produces significant anticancer effect on human A549 lung cancer cells and human breast cancer cells [5-7]. Therefore, the incorporation of $\mathrm{CQ}$ (or HCQ) and various DOX formulations may improve the reversal of MDR and enhance tumor treatment efficacy. In a previous work [8], self-assembled folate-phytosterol-carboxymethyl cellulose nanoparticles (FPCMC NPs) derived from plant materials were fabricated and used as carriers of anticancer drugs. In this study, the combined inhibitory effects of DOX/FPCMC NPs and HCQ on human lung cancer cell lines (A549 cells) were investigated with respect to cytotoxicity, targeted ligand competition, cell proliferation inhibition and cellular drug uptake.

The study was aimed at evolving new strategies for overcoming MDR associated with traditional anticancer drugs.

\section{EXPERIMENTAL}

\section{Materials}

Doxorubicin (DOX) hydrochloride and HCQ were brought from Nanjing Oddfoni Biological Technology Co. Ltd (Nanjing, China). 3-(4,5Dimethylthiazol-2-yl)-2,5-diphenyltetrazolium bromide (MTT) cell proliferation and cytotoxicity assay kit, Hoechst 33342, DMEM medium, fetal bovine serum (FBS), phosphate-buffered saline (PBS), 4\% paraformaldehyde and folate were products of Sangon Biotech Co. Ltd (Shanghai, China). All other reagents used were of analytical grade. Ultrapure water (18.25 MX) was used throughout the study.

\section{Cell line and culture conditions}

Human A549 lung adenocarcinoma cell line was used. The cells were cultured in DMEM appended with $10 \%$ fetal bovine serum (FBS) and $1 \%$ penicillin-streptomycin in a humidified 5 $\% \mathrm{CO}_{2}$ incubator at $37{ }^{\circ} \mathrm{C}$. Cells harvested in logarithmic growth phase were used and all experiments were carried out at least three times on different days.

\section{Cell viability}

The cytotoxicities of blank FPCMC NPs, free DOX and DOX/FPCMC NPs against A549 cells were determined using MTT assay. The procedures used in preparation of the blank and drug-loaded FPCMC NPs in different formulations and drug concentrations were as indicated in a previous study [8]. The A549 cells in logarithmic growth phase were seeded in 96well culture plates at a density of $5 \times 10^{3}$ cells/well, and cultured at $37{ }^{\circ} \mathrm{C}$ for $12 \mathrm{~h}$ in a humidified atmosphere containing $5 \% \quad \mathrm{CO}_{2}$. Then, the culture medium was replaced with a fresh medium containing blank FPCMC NPs, HCQ alone, free DOX, DOX/FPCMC NPs, free $\mathrm{DOX}+\mathrm{HCQ}$, or DOX/FPCMC NPs + HCQ (in free DOX + HCQ or DOX/FPCMC NPs + HCQ group, the cells were pretreated with $\mathrm{HCQ}$ for $2 \mathrm{~h}$ prior to exposure to free group DOX or DOX/FPCMC NPs). The concentrations of HCQ, DOX and FPCMC NPs varied within the ranges of $20-120 \mu \mathrm{mol} / \mathrm{L}, 2-12 \mathrm{mg} / \mathrm{L}$ and $50-500$ $\mathrm{mg} / \mathrm{L}$, respectively.

Each drug concentration was repeatedly tested in five separate wells, and cells without any drug treatment were used as control. After $48 \mathrm{~h}$ of incubation, the cells were washed twice with cold PBS, and $100 \mu \mathrm{L}$ of fresh culture medium containing MTT reagent $(0.5 \mathrm{mg} / \mathrm{mL})$ was added to each well, followed with incubation for $4 \mathrm{~h}$. Then, the MTT solution in each well was removed, and the resultant formazan crystals were solubilized with $100 \mu \mathrm{L}$ of DMSO, with continuous shaking for $10 \mathrm{~min}$. Finally, the percentage of cell viability in each well relative to blank control group was measured after obtaining absorbance at wavelength of $570 \mathrm{~nm}$ using a microplate reader (TECAN Spark, Switzerland).

\section{Free folate competition}

In a previous study, it was demonstrated that folate receptors were overexpressed on the membranes of A549 cells [9-14]. In the current study, the competitive inhibition of folate on the anticancer activity of DOX/FPCMC NPs was 
investigated using MTT assay. The A549 cells were seeded in 96-well plates at a density of $5 \times$ $10^{3}$ cells/well, and incubated for $12 \mathrm{~h}$. Then, the culture medium in each well was replaced with fresh culture medium containing varying concentrations of free folate (concentration range: $0-500 \mathrm{mg} / \mathrm{L}$ ) and fixed concentrations of DOX/FPCMC NPs (DOX: $8 \mathrm{mg} / \mathrm{L})$. Subsequently, the procedures used for cell culture and viability test were the same used in the MTT assay described under 'Cell viability'.

\section{Wound healing assay}

The wound healing assay was used to determine the inhibitory effects of the drugs on the proliferation and migration of A549 cells. In this assay, A549 cells were seeded in 35- $\mathrm{mm}$ petri dishes at a density of $5 \times 10^{5}$ cells/dish, and cultured for $12 \mathrm{~h}$ to make the cells attach and grow to $80 \%$ confluence. Then, a linear scratch wound was generated with a $200-\mu \mathrm{L}$ sterile pipette tip on the cell monolayer in every dish, and the detached cells were removed via washing twice with cold PBS. The scratched cell monolayer was incubated for $48 \mathrm{~h}$ in fresh culture medium containing fixed concentration of $\mathrm{HCQ}$, free DOX, DOX/FPCMC NPs, free DOX + HCQ (pretreatment with $\mathrm{HCQ}$, followed with addition of DOX), or DOX/FPCMC NPs + HCQ (HCQ pretreatment, followed with addition of DOX/FPCMC NPs). The concentrations of HCQ and DOX were $20 \mu \mathrm{M}$ and $4 \mathrm{mg} / \mathrm{L}$, respectively. Untreated cell monolayer served as control. After incubation, the samples were washed thrice with cold PBS and fixed with $4 \%$ paraformaldehyde. Then, wound healing was quantified through measurement of wound width under an inverted microscope (Olympus IX7, Japan) using Image J software. Wound healing (R) was calculated as shown in Equation 1:

$R(\%)=\left(W_{0}-W\right) / W_{0} \times 100$

where $W_{0}$ and $W$ are the wound edge widths of sample at 0 and $48 \mathrm{~h}$, respectively.

\section{Cellular uptake of drugs}

The uptake and intracellular distribution of free DOX and DOX/FPCMC NPs in A549 cells were determined and compared using CLSM (Olympus FV1000, Japan). The cells were seeded in confocal dishes at a density of $5 \times 10^{5}$ cells/dish, and were cultured for $12 \mathrm{~h}$. Thereafter, the cells were incubated in fresh culture medium containing fixed concentration of free DOX or DOX/FPCMC NPs (DOX: $5 \mathrm{mg} / \mathrm{L}$ ) for $4 \mathrm{~h}$. The cells were subsequently washed thrice with cold PBS, fixed with $4 \%$ paraformaldehyde for 30 min, and nucleus-stained with Hoechst 33342 . The fluorescence of DOX (red) and Hoechst 33342 (blue) were measured with CLSM to reveal the cellular uptake and internalization of the different drug formulations.

\section{Statistical analysis}

Data are expressed as mean \pm standard deviation. Two-tailed student's t-test and OneWay ANOVA were used for statistical analyses of differences. All statistical analyses were done with IBM SPSS statistic software. Statistical significance was assumed at $p$ value less than 0.05 (95\% confidence interval).

\section{RESULTS}

\section{Cytotoxicity}

As shown in Figure 1, the blank FPCMC NPs produced no cytotoxicity on A549 lung cancer cells in the tested concentration range (up to 500 $\mathrm{mg} / \mathrm{l}$ ). The cytotoxicities of various drug formulations are shown Figure 2. The results showed that HCQ alone, free DOX and DOX/FPCMC NPs exerted concentrationdependent cytotoxicity against A549 cells, with $I_{50}$ values (concentrations that result in inhibition of half of the cells) of $78.5 \mu \mathrm{mol} / \mathrm{L}, 7.32$ $\mathrm{mg} / \mathrm{L}$ and $5.57 \mathrm{mg} / \mathrm{L}$, respectively. The fact that DOX/FPCMC NPs exhibited stronger cytotoxicity than free DOX of same concentration suggested that the folate-receptor-mediated endocytosis enhanced the anticancer activity of DOX. It was found that the combination of HCQ with DOX or DOX/FPCMC NPs resulted in significantly better suppression of cell viability than DOX alone or $\mathrm{HCQ}$. The results indicated that the $\mathrm{IC}_{50}$ of free DOX + HCQ to A549 cells was decreased to about $3.73 \mathrm{mg} / \mathrm{L}$. The DOX/FPCMC NPs + HCQ produced even higher cytotoxicity against A549 cells than free DOX + HCQ NPs, with $\mathrm{IC}_{50}$ as low as $1.92 \mathrm{mg} / \mathrm{L}$. These results indicate that the antitumor effect of free DOX or DOX/FPCMC NPs was significantly increased in the presence of $\mathrm{HCQ}$.

\section{Folate competitive inhibition}

Folate competition assay was used to determine the role of free folate in targeted delivery of DOX/FPCMC NPs into A549 cells. As shown in Figure 3 , the cytotoxicity of DOX/FPCMC NPs against A549 cells was inhibited by free folate in a concentration-dependent manner. For instance, cell viability was $41.6 \%$ in folate-free culture medium, but the value soared to $72.4 \%$ in culture medium containing $500 \mathrm{mg} / \mathrm{L}$ of free folate. These results indicate that the cellular 
uptake of DOX/FPCMC NPs was effectively inhibited by free folate molecules through competitive binding to the folate receptors on the A549 cell membrane surface.

\section{Inhibition of cell migration}

The effect of various drug formulations on the proliferation and migration of A549 cells was assessed with wound healing assay. As shown in Figure. 4, DOX/FPCMC NPs + HCQ produced the strongest inhibitory effect on the migration of A549 cells, with wound-healing of only $4.3 \%$ after $48 \mathrm{~h}$.

This indicates synergism between DOX/FPCMC NPs and HCQ in the suppression of the proliferation and migration of A549 cells. After 48 $h$, the wound-healing due to free DOX + HCQ, DOX/FPCMC NPs, free DOX and HCQ alone were $13,28,59$ and $64 \%$, respectively. In contrast, the wound width of A549 cell monolayer in the control group became very narrow, leaving only a small gap.

\section{Cellular uptake path}

Small molecule drugs e.g. DOX, enter the cytoplasm of cells through passive diffusion driven by concentration gradients. However, due to MDR, most drugs are expelled from cells by Pglycoprotein pumps located on the cell membrane. However, once DOX enters the nucleus, it binds to DNA and kills the cell. Macromolecules like NPs usually enter the cells through endocytosis, thereby escaping the efflux action of P-glycoprotein [15].

The CLSM images of A549 cells incubated with free DOX or DOX/FPCMC NPs are presented in Figure 5. The red fluorescence of DOX was utilized to locate the position of the drug in the cells. The cell nucleus was stained with Hoechst 33342 (blue fluorescence). After incubation for 4 $h$ with free DOX, weak DOX fluorescence was observed in A549 cells. However, in cells incubated with DOX/FPCMC NPs, strong drug fluorescence was spotted in the cytoplasm. The amount of drug in A549 cells treated with DOX/FPCMC NPs was significantly higher than that from free DOX-treated cells at the same DOX concentration. In addition, it was seen that DOX/FPCMC NPs were primarily located in the cytoplasm rather than the nucleus because of folate receptor-mediated endocytosis. The result of cellular uptake suggested that the endocytosis resulted in higher uptake of drug, which in turn produced better antitumor effect.

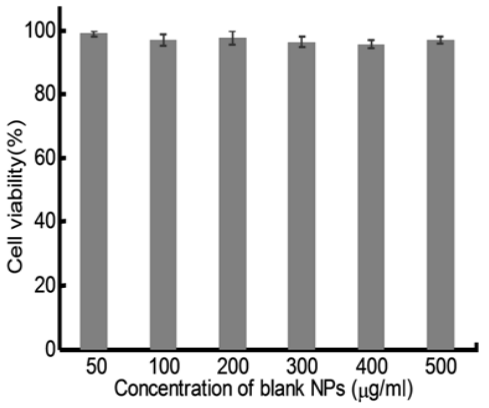

Figure 1: Viability of A549 cells exposed to blank FPCMC NPs. Data are expressed as mean \pm SD $(n=$ 5)

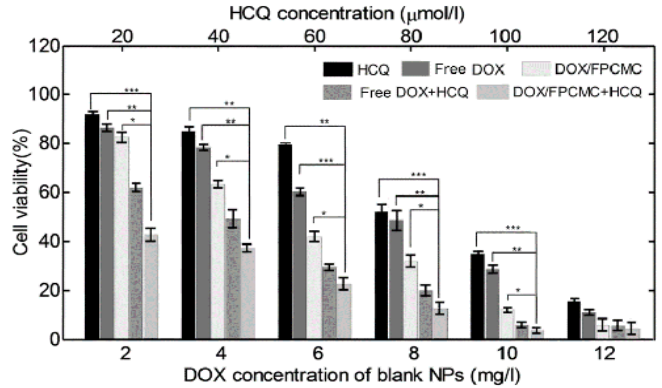

Figure 2: Viability of $A 549$ cells exposed to $\mathrm{HCQ}$ alone, free DOX, DOX/FPCMC NPs, free DOX + HCQ or DOX/FPCMC NPs + HCQ, respectively. Data are expressed as mean $\pm \mathrm{SD}(\mathrm{n}=5)$; ${ }^{*} p<0.05,{ }^{* *} p<0.01$, ${ }^{* * *} p<0.001$

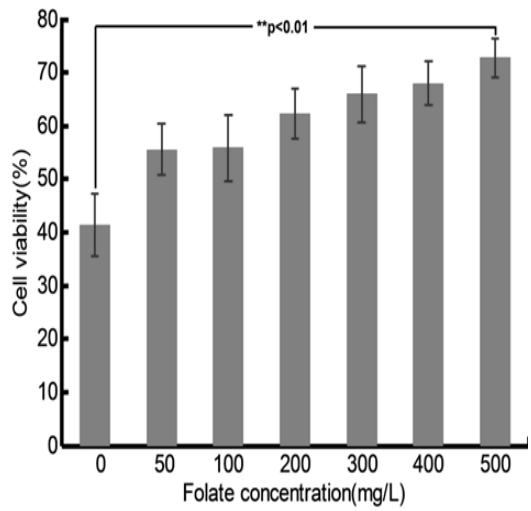

Figure 3: Effect of free folate on viability of A549 cells exposed to DOX/FPCMC NPs. Data are expressed as mean $\pm \mathrm{SD}(\mathrm{n}=5) ;{ }^{*} p<.05$

\section{DISCUSSION}

In this study, self-assembled FPCMC NPs were utilized as effective carrier system to deliver DOX into A549 cells for cancer therapy. The drugloaded FPCMC NPs exhibited high drug-targeted delivery efficiency and good tumor suppressive effect. Among the various drug formulations, the combination of DOX/FPCMC NPs and HCQ resulted in the highest cytotoxicity and highest inhibition of migration in A549 cells. 

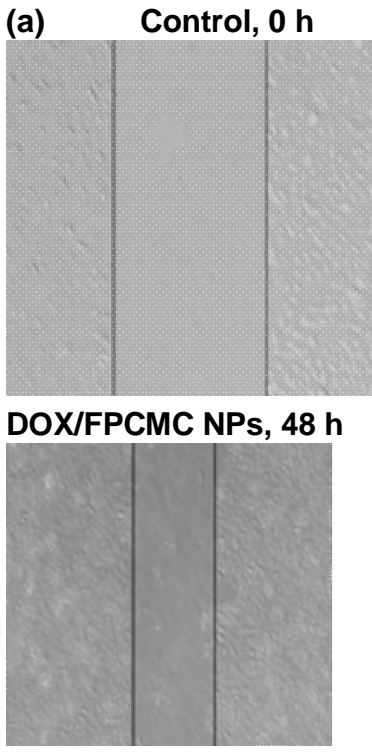

Control, $48 \mathrm{~h}$

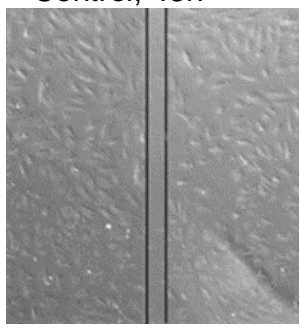

DOX/FPCMCNPs + HCQ, 48 h

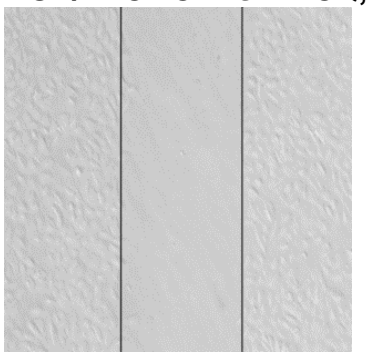

Free DOX, $48 \mathrm{~h}$

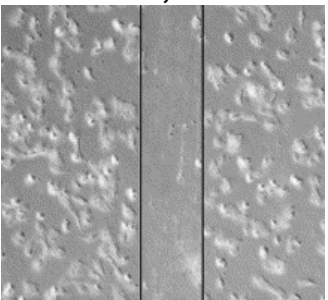

(b)

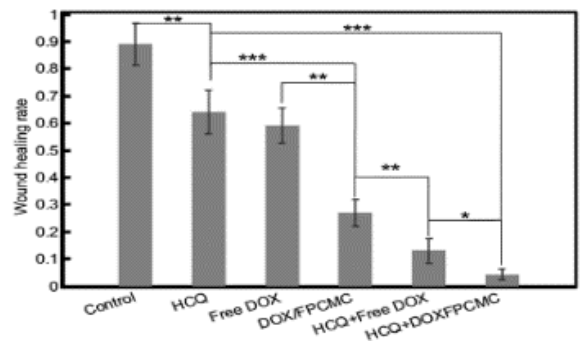

Figure 4: Results of wound healing assay in A549 cells treated with $\mathrm{HCQ}$ alone, free DOX, DOX/FPCMC NPs, free DOX + HCQ or DOX/FPCMC NPs + HCQ (a): wound healing of various drug formulations; (b): comparison of $\%$ wound healing among treatment groups (mean $\pm \mathrm{SD} ; \mathrm{n}=3$ ); ${ }^{*} p<0.05,{ }^{* *} p<0.01,{ }^{* * *} p<0.001$

A
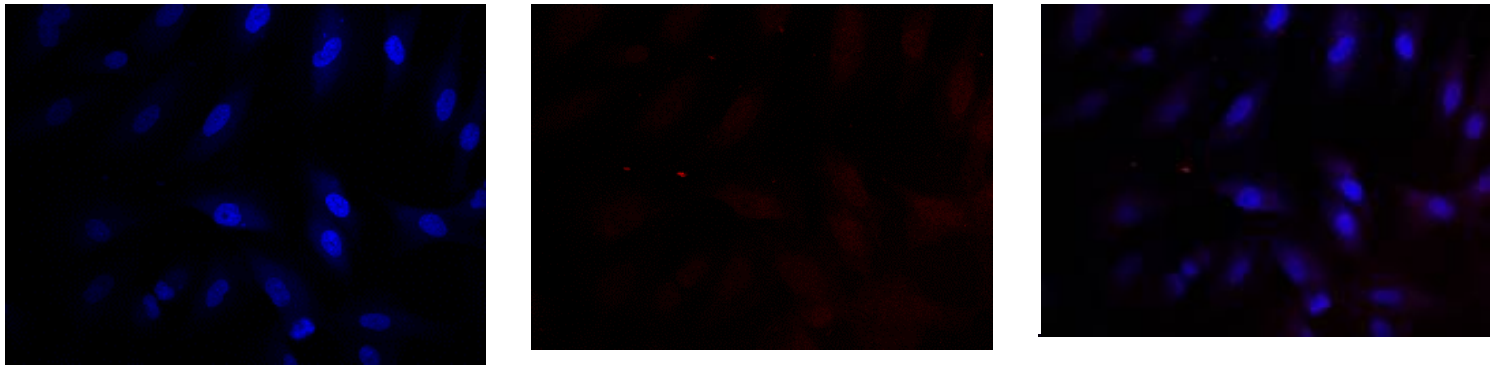

B
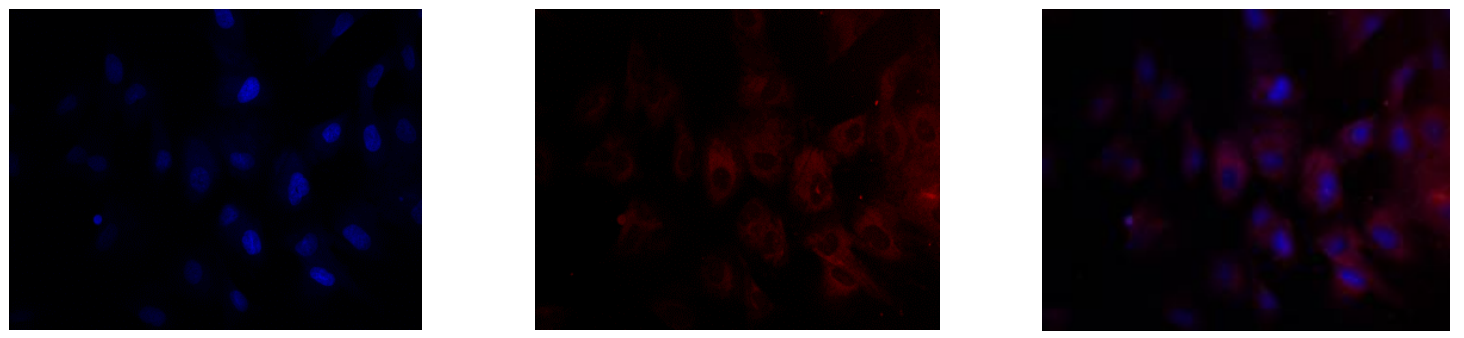

Figure 5: CLSM images of A459 cells exposed to free DOX (A) and DOX/FPCMC NPS (B) at the same DOX concentration for $4 \mathrm{~h}$ 
The fact that free folate competitively inhibited the cytotoxicity of DOX/FPCMC NPs against A549 cells indicate that the drug-loaded FPCMC NPs specifically targeted folate-receptoroverexpressing cancer cells. The DOX/FPCMC NPs had higher cellular uptake than free DOX.

\section{CONCLUSION}

The results of this study have demonstrated that DOX/FPCMC NPs enhance drug concentration in target cells, increase the anticancer effect of DOX, and reduce the toxic and side effects of DOX. When used with HCQ, DOX/FPCMC NPs might reverse MDR of tumor cells.

\section{DECLARATIONS}

\section{Acknowledgement}

This study was financially supported by Key Laboratory of Bioresource Protection and Utilization of Anhui Province, Key Laboratory of Biotic Environment and Ecological Safety of Anhui Province, Key Laboratory of Biomedicine in Gene Diseases and Health of Anhui Higher Education Institutes, Anhui Normal University, and the Innovation Team of Scientific Research Platform in Anhui Universities.

\section{Conflict of interest}

No conflict of interest is associated with this study.

\section{Contribution of authors}

We declare that this work was done by the authors named in this article and all liabilities pertaining to claims relating to the content of this article will be borne by the authors. Ezzat $\mathrm{H}$ Elshazly and Song Zhang contributed equally to this work.

\section{Open Access}

This is an Open Access article that uses a funding model which does not charge readers or their institutions for access and distributed under the terms of the Creative Commons Attribution License (http://creativecommons.org/licenses/by/ 4.0) and the Budapest Open Access Initiative (http://www.budapestopenaccessinitiative.org/rea d), which permit unrestricted use, distribution, and reproduction in any medium, provided the original work is properly credited.

\section{REFERENCES}

1. Li S, Sun Z, Meng X, Meng X, Deng G, Zhang J, Zhou K, Li W, Zhou L, Gong P, Lintao C. Targeted methotrexate prodrug conjugated with heptamethine cyanine dye improving chemotherapy and monitoring itself activating by dual-modal imaging. Front Mater 2018; 5: 35

2. Wilson TR, Johnston PG, Longley DB. Anti-apoptotic mechanisms of drug resistance in cancer. Curr. Cancer Drug Tar 2009; 9: 307-319.

3. Amaravadi RK, Lippincott-Schwartz J, Yin X.-M, Weiss WA, Takebe N, Timmer W, DiPaola RS, Lotze MT, White E. Principles and current strategies for targeting autophagy for cancer treatment. Clin Cancer Res 2011; 17: 654-666.

4. Janku F, McConkey DJ, Hong DS, Kurzrock $R$. Autophagy as a target for anticancer therapy. Nat Rev Clin Oncol 2011; 8: 528-539.

5. Fan $C$, Wang $W$, Zhao $B$, Zhang $S$, Miao J. Chloroquine inhibits cell growth and induces cell death in A549 lung cancer cells. Bioorg Med Chem 2006; 14: 3218-3222.

6. Kim EL, Wüstenberg R, Rübsam A, Schmitz-Salue C, Warnecke G, Bücker EM, Pettkus N, Speidel D, Rohde $V$, Schulz-Schaeffer $W$ et al. Chloroquine activates the p53 pathway and induces apoptosis in human glioma cells. Neuro Oncol 2010; 12: 389-400.

7. Maycotte $P$, Aryal S, Cummings CT, Thorburn J, Morgan MJ, Thorburn A. Chloroquine sensitizes breast cancer cells to chemotherapy independent of autophagy. Autophagy 2012; 8: 1-13

8. Elshazly HE, Yu L, Zhang $Y$, Wang $H$, Chen $K$, Zhang $S$, Ke L, Gong R. Fabrication of folate-phytosterolcarboxymethyl cellulose nanoparticles derived from plant material as carrier of anticancer drug. Micro \& Nano Letters 2019: 14: 1111-1116

9. Muthukumar $T$, Chamundeeswari M, Prabhavathi $S$, Gurunathan B, Chandhuru J, Sastry TP. Carbon nanoparticle from a natural source fabricated for folate receptor targeting, imaging and drug delivery application in A549 lung cancer cells. Eur J Pharm Biopharm 2014; 88: $730-736$.

10. Piras S, Carta A, Briguglio I, Corona p, Paglietti G, Luciani R, PaolaCosti M, Ferrari S. 2-[N-Alkyl (Rphenyl)-aminomethyl]- 3-phenyl-7rifluoromethylquinoxalines as anticancer agents inhibitors of folate enzymes. Eur J Med Chem. 2014; 75 : 169-183.

11. Hu L, Pang $S$, Hu $Q$, Gu $D$, Kong $D$, Xiong $X$, Su J. Enhanced antitumor efficacy of folate targeted nanoparticles co-loaded with docetaxel and curcumin. Biomed Pharmacother 2015; 75: 26-32.

12. Kato $T$, Jin CS, Ujiie $H$, Lee $D$, Fujino $K$, Wada $H, H u H P$, Weersink RA, Chen J, Kaji M. Nanoparticle targeted folate receptor 1-enhanced photodynamic therapy for lung cancer. Lung Cancer 2017; 113: 59-68.

13. Singh RP, Sharma $G$, Sonali, et al. Chitosan-folate decorated carbon nanotubes for site specific lung cancer delivery. Mater Sci Eng 2017; 77: 446-458.

Trop J Pharm Res, February 2020; 19(2): 224 
Elshazly et al

14. Tanino R, Tsubata $Y$, Harashima $N$, Harada M, Isobe $T$. Novel drug-resistance mechanisms of pemetrexedtreated non-small cell lung cancer. Oncotarget 2018; 9 : 16807-16821.
15. Kedar U, Phutane P, Shidhaye S, Kadam V. Advances in polymeric micelles for drug delivery and tumor targeting Nanomedicine: Nanotechnol, Biol Med 2010; 6: 714729. 